\title{
WORKPLACE Signaling ANd FinanCial COMMitMEnt: EVIDENCE FROM A FIELD EXPERIMENT
}

\author{
Emily Breza, Martin Kanz, and Leora Klapper
}

ONLINE APPENDIX

\section{A1. Analyzing the Savings Experiment: Theoretical Framework}

In this section, we develop a stylized framework based on the canonical signaling model of Spence (1973) to facilitate the analysis and match our experimental design.

\section{THE FIRM's PROBLEM}

Suppose that workers are heterogeneous in their intended time horizon of employment at the firm, $\theta_{i} \sim U[0,1]$. The firm must decide whether to invest in extra training for each worker. Doing so incurs a cost $c_{I}$ and a benefit, which depends on how long the worker stays at the firm, $\theta_{i}$. Assume that there exists $\theta^{*}$ where $0<\theta^{*}<1$, such that the firm is indifferent to investing in that worker, $\theta^{*}=c_{I}$. If the firm could observe worker type, then it would invest in all workers with $\theta_{i} \in\left[\theta^{*}, 1\right]$. However, if all workers receive benefit from the training $w$ and pay no cost, workers would not be willing to voluntarily reveal $\theta_{i}<\theta^{*}$. Suppose that $c_{I}>\frac{1}{2}$, so with no additional information, the firm chooses not to invest in any worker.

\section{Worker Sign-Up Decisions Without Endorsement or Disclosure}

Next, let's consider what happens when the factory introduces a commitment savings product for workers. Workers obtain a benefit from opening a commitment savings account, but pay a cost if they terminate the contract early. The expected benefit from the account is increasing in the worker's duration of employment with the firm, and denoted $s \theta_{i}$. The cost of immediate termination of the account is $\kappa>w$. Because the penalty cost from early withdrawal is decreasing with the worker's employment horizon, the worker's cost is also a function of $\theta_{i}$. In absence of any signaling motive, the net benefit from opening an account is $s \theta_{i}-\kappa\left(1-\theta_{i}\right)$. Thus, when information is not communicated to the firm, workers will sign up for the product when $\theta_{i} \geq \frac{\kappa}{\kappa+s} \equiv \theta^{C}$.

\section{WORKER SIGN-Up DECISIONS WITH ENDORSEMENT ONLY}

Next, we allow the employer's endorsement to affect the worker's beliefs about the value of the product. Post endorsement, the worker's expected benefit is now $\left(s+s_{E}\right) \theta_{i}$. Thus, workers will decide to sign up for the commitment savings product if $\theta_{i} \geq \frac{\kappa}{s+s_{E}+\kappa} \equiv \theta^{E E}$.

Note that if $s_{E}>0$, then $\theta^{E E}<\theta^{C}$, leading to higher take-up rates in the endorsement only condition relative to the control. Conversely, if $s_{E}<0$, then $\theta^{E E}>\theta^{C}$, leading to lower take-up rates under the endorsement only treatment relative to the control.

\section{Worker Sign-Up DeCISIONS WITH ENDORSEMENT AND DisClosure}

We next turn to the problem facing the worker and the firm when information about the sign-up decision is transmitted to management and when workers are aware that the firm endorses the product. Now the worker is able to use her sign-up decision to send a costly signal of her commitment to stay employed with the firm to management. We consider a separating equilibrium where the firm invests in the worker if and only if the worker signs up for the product. We assume that participating in the training program is worth $w \theta_{i}$ to the worker, and that the firm is unable to charge the worker for the training. We also assume that $\frac{1}{2}+\frac{1}{2} \theta^{E E-E D} \geq c_{I}$. In addition, we allow workers to dislike sharing their private information with the firm. This leads to a decrease in utility of $\eta_{D} \theta_{i}$, which is also increasing in the worker's horizon with the firm. 
In this separating equilibrium, worker payoffs are normalized to 0 if the worker does not sign up for the product. Therefore, the worker will sign up for the product if

$$
\left(w+s+s_{E}-\eta_{D}\right) \theta_{i}-\kappa\left(1-\theta_{i}\right) \geq 0
$$

All workers with $\theta_{i} \geq \frac{\kappa}{w+s+s_{E}-\eta_{D}+\kappa} \equiv \theta^{E E-E D}$ will sign up for the account. We need to confirm that this is indeed an equilibrium, and that the firm does not have any incentive to deviate from the strategy of investing only in workers who sign up for the product. We know already that it is not profitable to invest in all workers. Therefore, we need to check that the expected value of investing in workers who sign up is weakly positive. The expected type of workers taking up the product is $\frac{1}{2}+\frac{1}{2} \theta^{E E-E D}$, so it is optimal to invest as long as $\frac{1}{2}+\frac{1}{2} \theta^{E E-E D} \geq c_{I}$, which we assumed above.

\section{WORKER Sign-Up DeCisions WITH Disclosure ONLY}

Finally, we consider the case where information about the worker's sign-up decision is disclosed to the employer, but there is no employer endorsement. Here, in addition to $s_{E}=0$, we also allow workers to be uncertain about how the firm uses the sign-up information. That is, workers believe that they are in a signaling equilibrium with probability $p_{D} \leq 1$ and that the firm doesn't base wages on sign-up with probability $1-p_{D}$. Now, workers experience utility of

$$
\left(p_{D} w+s-\eta_{D}\right) \theta_{i}-\kappa\left(1-\theta_{i}\right)
$$

from signing up. Therefore, all individuals with $\theta_{i} \geq \frac{\kappa}{p_{D} w+s-\eta_{D}+\kappa} \equiv \theta^{E D}$ will take up the account.

Once more, we need to ensure that this is indeed a separating equilibrium, and that the firm that does choose to use the information has no profitable deviation. This will be true so long as $\frac{1}{2}+\frac{1}{2} \theta^{E D} \geq c_{I}$.

\section{A2. Appendix Tables}

\begin{tabular}{|c|c|c|c|c|c|}
\hline & $\begin{array}{c}\text { (1) } \\
\text { Observations }\end{array}$ & $\begin{array}{c}(2) \\
\text { Mean }\end{array}$ & $\begin{array}{c}(3) \\
\text { StDev }\end{array}$ & $\begin{array}{l}(4) \\
\text { Min }\end{array}$ & $\begin{array}{c}(5) \\
\text { Max }\end{array}$ \\
\hline \multicolumn{6}{|l|}{ Panel A: Savings experiment [N=942] } \\
\hline Signed up=yes & 244 & 0.041 & 0.198 & 0 & 1 \\
\hline Term, years & 244 & 0.299 & 1.347 & 0 & 10 \\
\hline \multicolumn{5}{|l|}{ Worker characteristics } & 2,000 \\
\hline Male $=1$ & 942 & 0.677 & 0.468 & 0 & 1 \\
\hline Salary, Bangladeshi Taka & 942 & 6,392 & 256.5 & 5,678 & 6,805 \\
\hline Intended tenure, years & 935 & 2.720 & 1.704 & 0 & 6 \\
\hline \multicolumn{6}{|l|}{ Panel B: Worker evaluation experiment } \\
\hline & Observations & Mean & StDev & Min & Max \\
\hline \multicolumn{6}{|l|}{ Evaluation ratings } \\
\hline Production performance & 608 & 17.237 & 3.913 & 8 & 20 \\
\hline Promotion perspective & 608 & 16.737 & 4.077 & 4 & 20 \\
\hline Probability of staying & 608 & 17.053 & 4.528 & 4 & 20 \\
\hline Overall rating & 608 & 51.026 & 9.927 & 20 & 60 \\
\hline \multicolumn{6}{|c|}{$\begin{array}{l}\text { Note: The table shows summary statistics for the savings experiment (Panel A) and for the worker evaluation experiment (Panel } \\
\text { B). Experimental outcomes are reported for the control group only. Worker characteristics are self-reported and taken from a survey } \\
\text { administered at the time of the savings experiment. The ratings scale follow the firm's standard format, in which managers assign scores } \\
\text { from } 1 \text { (worst) to } 5 \text { (best) and these are multiplied by four for each category so that the maximum attainable score is } 100 \text {. Managers } \\
\text { in the experiment were asked to rate only the three categories they could assess based on the information in the worker file (without } \\
\text { knowing the identity or having interacted with the worker), so that } 60 \text { was the maximum attainable evaluation score in the experiment. }\end{array}$} \\
\hline
\end{tabular}

TABLE A1-SUMMARY STATISTICS 
TABLE A2-WORKER EVALUATION EXPERIMENT: WHAT SIGNAL IS BEING EXTRACTED?

\begin{tabular}{|c|c|c|c|c|}
\hline & (1) & (2) & (3) & (4) \\
\hline Evaluation rating: & $\begin{array}{c}\text { Production } \\
\text { performance }\end{array}$ & $\begin{array}{l}\text { Promotion } \\
\text { prospects }\end{array}$ & $\begin{array}{l}\text { Employment } \\
\text { time horizon }\end{array}$ & $\begin{array}{l}\text { Total } \\
\text { score }\end{array}$ \\
\hline Signed up=yes, 1-year term & $\begin{array}{c}0.703 \\
(0.519)\end{array}$ & $\begin{array}{c}0.305 \\
(0.558)\end{array}$ & $\begin{array}{c}1.376^{* *} \\
(0.589)\end{array}$ & $\begin{array}{c}2.384 \\
(1.487)\end{array}$ \\
\hline Signed up=yes, 5-year term & $\begin{array}{l}0.919 * \\
(0.484)\end{array}$ & $\begin{array}{c}0.686 \\
(0.467)\end{array}$ & $\begin{array}{c}1.632 * * * \\
(0.537)\end{array}$ & $\begin{array}{c}3.237 * * \\
(1.280)\end{array}$ \\
\hline Signed up $=$ no & $\begin{array}{c}0.064 \\
(0.451)\end{array}$ & $\begin{array}{l}-0.038 \\
(0.405)\end{array}$ & $\begin{array}{l}-0.335 \\
(0.333)\end{array}$ & $\begin{array}{l}-0.310 \\
(0.935)\end{array}$ \\
\hline Observations & 608 & 608 & 608 & 608 \\
\hline R-squared & 0.079 & 0.044 & 0.072 & 0.086 \\
\hline Session fixed effects & Yes & Yes & Yes & Yes \\
\hline Worker file fixed effects & Yes & Yes & Yes & Yes \\
\hline Clustered SE & Manager & Manager & Manager & Manager \\
\hline Mean rating (control) & 17.24 & 16.74 & 17.05 & 51.02 \\
\hline \multicolumn{5}{|c|}{$\begin{array}{l}\text { Note: The table reports results of the worker evaluation experiment. Each column reports results of a separate regression. The dependent } \\
\text { variable in column (1) is the rating for overall production performance assigned to the worker by the manager. The dependent variable } \\
\text { in column (2) is the rating for the worker's perspective to be promoted to a supervisor position. The dependent variable in column } \\
\text { (3) is the rating for the anticipated tenure of the worker in the job. The dependent variable in column (4) is the sum of the worker } \\
\text { ratings assigned by the manager. Standard errors, clustered at the manager level, are reported in parentheses. *, **, and *** indicate } \\
\text { significance at } 10 \%, 5 \% \text {, and } 1 \% \text {, respectively. }\end{array}$} \\
\hline
\end{tabular}

